\title{
Pulmonary Effects of Diesel Exhaust
}

\section{Neutrophilic Inflammation, Oxidative Injury, and Asthma}

\author{
Nicholas Kenyon* and Fu-Tong Liu ${ }^{\dagger \ddagger}$ \\ From the Division of Pulmonary Medicine," Department of \\ Medicine, Department of Dermatology, ${ }^{\dagger}$ School of Medicine, \\ University of California, Davis, California; and the Institute of \\ Biomedical Sciences, ${ }^{\ddagger}$ Academia Sinica, Taiwan
}

Diesel exhaust particulates (DEPs) have the capacity to affect lung growth and cause systemic health effects. Recent epidemiologic studies have highlighted the difficulties in understanding the contribution of traffic-related DEPs to allergy and asthma. In this issue of The American Journal of Pathology, Kim et $\mathrm{al}^{1}$ investigated the effect of DEPs on the inflammatory response and airway hyperresponsiveness induced by allergens in a mouse model of asthma. The investigators found that mice exposed to house dust mite extract (HDE) in combination with DEP (HDE/DEP) showed a marked increase in mucus production and greater airway resistance compared with those receiving only HDE. This effect was partly mediated by the neutrophil chemokines KC and macrophage inflammatory protein (MIP)-2. These interesting findings further illustrate the important interaction between DEP exposure and asthma. We discuss the investigators' findings in light of other recent research efforts in ambient pollution, DEP, and lung health.

\section{Multiple Causes of Asthma}

Asthma increasingly is described as a syndrome rather than a single disease. Indeed, numerous exposuresviral infections, indoor as well as outdoor aeroallergens, and ambient pollution - contribute to the development of asthma in childhood and the persistence of asthma in adulthood. Environmental influences weigh heavily on early lung growth, particularly traffic-related pollution, including DEPs. DEPs are primarily ultrafine $(0.1 \mu \mathrm{m}$ diameter) particulates that have the capacity to penetrate the lung down to the alveoli and cause systemic effects. Diesel truck engines are reported to be the primary producers of DEPs and account for the majority of the ambient particulate matter (PM) in urban environments. ${ }^{2}$
Many epidemiologic studies have reported correlations between asthma (prevalence or symptoms) and exposure to either traffic pollution or DEPs specifically. A few have commented on correlations with allergic inflammation and increased serum IgE levels and suggested a dose- and time-dependent sensitization effect also. Taken together, however, the results of these epidemiologic studies have been maddeningly inconsistent. In 2005, the World Health Organization wrote that although there were good data to suggest a correlation between traffic pollution and respiratory symptoms, there was no correlation with atopic asthma. ${ }^{3}$

\section{Increased Risk for Asthma in Childhood}

Children appear to be at increased risk of lung toxicity from traffic-related pollution because their lungs are not fully developed and because of pollution dose. ${ }^{4,5}$ Children exercise outside and their exposure to PM is increased compared with adults in the same environment. Alveolar number increases at least 10-fold in the first 4 years of life (from approximately 20 million to 260 million), and increased exposure to polluted air at a young age could adversely affect alveolar budding, lung growth, and airway epithelial development. ${ }^{6}$ In addition, children have imperfect airway epithelial barriers and immature immune systems, and it is reasonable to hypothesize that PM penetrates the airway epithelium in children to a greater degree than in adults, thus interacting more with dendritic cells and altering immune system development.

\section{Epidemiologic Studies, the Link between DEP and Asthma Is Inconclusive}

Three recent epidemiologic studies highlighted the difficulties with understanding the contribution of traffic-re-

\footnotetext{
Accepted for publication August 31, 2011.
}

CME Disclosure: None of the authors disclosed any relevant financial relationships.

Address reprint requests to: Fu-Tong Liu, M.D., Ph.D., Department of Dermatology, University of California, Davis, 3301 C St., Suite 1400, Sacramento, CA 95816. E-mail: fliu@ucdavis.edu. 
lated PM and DEPs to both allergy and asthma. In one cohort of 3515 Swedish children, traffic $\mathrm{PM}_{10}$-the surrogate for DEP — was not associated with either asthma or wheezing, but the combustion product and component of DEPs, nitrogen dioxide (NOx), was found to correlate with wheezing in children at ages 1 and 4. There was no correlation with physician-diagnosed asthma. ${ }^{7}$ In the subgroup of children with increased IgE levels, traffic NOx was associated with positive pollen sensitivity. It is difficult to know how to interpret these seemingly disparate results, but they do suggest that study of individual compounds or gases that cause oxidative stress, such as NOx, may be more illuminating than studying the complex DEPs. In another recent study, the International Study of Asthma and Allergies in Childhood study, more than 2100 fifth grade children were recruited from 40 schools in Rome. ${ }^{8}$ Ambient exposure to NOx was associated with reduced expiratory flow rates over several years, but there was no association with asthma symptoms or positive allergy tests. Finally, Spira-Cohen and colleagues ${ }^{9}$ reported a significant association between asthma and elemental carbon, the core of DEPs, measured by personal exposure monitors carried by asthmatic children in the South Bronx. Respiratory symptoms increased on high-traffic days and overall elemental carbon exposure, but not total $\mathrm{PM}_{2.5}$ or NOx levels, correlated best with these symptoms. Again, the investigators concluded that specific components of DEPS, such as elemental carbon, may be a much better indicator of adverse lung effects than more global $\mathrm{PM}_{2.5}$. Ultimately, epidemiologic studies fail to sort out whether the association between DEP and asthma leads to the development of asthma in children or to increased asthma attacks in children with established asthma. They do, however, provide significant clues to the components of traffic pollution and DEP that appear to confer the greatest threat to lung health.

\section{Mouse Model Using DEPs and HDE Implicates DEPs in Asthma}

Kim et $\mathrm{al}^{1}$ investigated the effect of DEPs on the inflammatory response and airways hyperresponsiveness (AHR) induced by allergens in a mouse model. They adopted a strategy designed to maximize the airway epithelial antigen penetration by using a combination of DEPs and HDE, which contains the allergens Bla g1 and Bla g2, to sensitize mice by three hypopharyngeal instillations on days 0,14 , and 21 , a procedure they developed earlier for induction of asthma-like responses in mice. ${ }^{10}$ One hour before each HDE challenge, they gave mice a DEP suspension by hypopharyngeal instillation. They measured AHR 2 hours after the last HDE challenge and then sacrificed the mice to collect samples.

The investigators found that mice receiving HDE in combination with DEPs (HDE/DEPs) showed a marked increase in mucus production and developed significantly higher airway resistance compared with those receiving only HDE. The most remarkable finding was that the former developed significantly more neutrophils in bronchoalveolar lavage (BAL) fluid compared with the latter. Consistent with that, these mice contained higher levels of two chemokines for neutrophils, KC and MIP-2, in both BAL fluid and lung homogenates.

\section{Increased Chemokines and Neutrophils in HDE/ DEP-Treated Alveoli}

To investigate whether these two chemokines contributed to the increased neutrophil response in mice exposed to HDE/DEPs, the investigators treated mice with neutralizing antibodies against these chemokines. They noted that the airway inflammatory response and AHR induced by HDE/DEPs were significantly suppressed by the treatment, so was the accumulation of airway mucins. Interestingly, mice treated with antibodies against these neutrophil-targeting chemokines also showed significantly reduced numbers of eosinophils in BAL fluid. This could be because these two chemokines also induce migration of eosinophils or the result of an indirect effect from the decreased neutrophil response. In this regard, it has been shown that neutrophils stimulated migration of eosinophils toward eosinophil chemoattractants. ${ }^{11}$ However, if this were the case, one would expect that DEP/ HDE treatment that causes an increase in the amount of neutrophils in the airways would result in a higher eosinophil response too, which was not observed in the current study.

\section{Oxidative Stress Increases in DEP/HDE-Treated Lungs}

Because cellular oxidative stress has been associated with the biological effects of DEPs, the investigators addressed the status of oxidative stress in mice treated with HDE/DEPs by using 8-iso prostaglandin F2 $\alpha$ (8-isoprostane) as a marker. They found that these mice contained significantly higher levels of isoprostane in BAL fluid compared with those treated with only HDE. This finding is in line with previous reports that PM induces oxidative stress. ${ }^{12,13}$ This can arise from the particulates' inherent oxidant-generating properties because they may contain soluble transition metals, such as iron, copper, chromium, and vanadium, on their surfaces, which can generate reactive oxygen species through Fenton-type reactions. ${ }^{14}$ With respect to DEPs specifically, these particles might contain surface functional groups with the capacity to form complexes with iron. ${ }^{15}$ In addition, in vitro studies showed that DEPs generated superoxide anions, which can lead to hydrogen peroxide $\left(\mathrm{H}_{2} \mathrm{O}_{2}\right)$ and hydroxyl radicals $(\cdot \mathrm{OH})$ without any biochemical or biological activation. ${ }^{16}$ Oxidative stress also can be driven by polycyclic aromatic hydrocarbons and quinones on the surface of PM. ${ }^{17}$

As mentioned by the investigators, oxidative stress may be able to explain a number of observations they made in their model with respect to the airway responses induced by DEPs. It is known that highly increased oxidative stress can induce proinflammatory cytokines and 
chemokines. For example, reactive oxygen species has been shown to increase the production of CXC chemokines. ${ }^{18,19}$ Oxidative stress also can promote airway smooth muscle contraction, thus augmenting AHR and mucin secretion. ${ }^{20}$

\section{Finding Common Ground among Multiple Studies}

Designing animal model studies to mimic human exposures and to elucidate the mechanisms of DEP-mediated lung injury are clearly complicated. Any model of mixed environmental exposures has limitations and is open to critiques of dose, timing, and delivery. Is a reductionist approach of using a single exposure better than a combination real-life strategy? It obviously depends on the question, but these issues are not trivial because the literature is brimming with examples of disparate results that appear wholly based on minor protocol differences or mouse strain differences. Understanding the common mechanisms underlying the different animal models will be important for both testing novel therapies and writing public health initiatives. One recent review nicely summarized and categorized the extensive animal model literature on DEPs and asthma. ${ }^{21}$

\section{The Role of Endotoxin Considered}

Both HDE and DEPs used in the current study contained endotoxin. The investigators found that in mice treated with DEPs without allergens, the number of neutrophils in the lung and the expression of CXC chemokines were close to the baseline and thus suggested that the low level of endotoxin in DEPs does not contribute to the increased pulmonary recruitment of neutrophils. However, it is known that endotoxin can modulate the airway inflammatory response induced by allergens, ${ }^{22}$ and thus may have a modulatory effect on neutrophil infiltrations.

In this regard, endotoxins are widely distributed in our living environment and thus their presence in both DEPS and HDE used in the current study in fact might mimic real-life situations. In humans, experimental exposure to endotoxins in the airways caused inflammation and alterations in the airway response directly and modulated airway responses to allergens. ${ }^{22}$ However, in epidemiologic studies both positive and negative associations have been noted with regard to the effect of endotoxins on the development of atopic diseases and asthma. ${ }^{23}$ There is a large amount of literature on the role of endotoxins in mouse models of asthma and there are conflicting reports with regard to the effects of endotoxins on the host airway responses to allergens. ${ }^{22}$

\section{Synergistic Response in Simultaneous Administration of DEPs and Allergen}

The role of DEPs in the development of atopy or allergy, such as allergic asthma and allergic rhinosinusitis, is less well studied, but equally important. Although the T-helper type $2\left(\mathrm{~T}_{\mathrm{H}} 2\right)$ cell cytokines IL-4 and IL-5 did increase after DEP exposure in this study, there was no increase in the number of eosinophils in the lung of the mice exposed to DEP plus HDE compared with the mice exposed to HDE alone. Other investigators, however, have shown a clear relationship between DEP exposure and the development of allergic sensitization. DEP exposure increased ovalbumin-specific IgE and Japanese Cedar-specific IgE in mice exposed to ovalbumin and Cedar, respectively. ${ }^{24}$ Draining thoracic lymph nodes from mice exposed to DEPs harbor $T$ cells with higher IL-4 secretory capacity in mice exposed to both ovalbumin and DEPs. ${ }^{25}$ Similar to what was found in this study, the propensity of the data support a synergistic effect when allergens and DEPs are given together. ${ }^{26,27}$ When given serially or alternately, however, the effect of the particulates is diminished or vanishes completely. ${ }^{28}$ Similar effects have been seen with combination treatments with allergens/ PM. ${ }^{29}$

\section{DEP Exposure Leads to $T_{H} 2$ Cell Maturation}

DEP also has been shown to potentiate T-cell maturation in draining lymph nodes by activating penetrating dendritic cells and stimulating increased production of the $\mathrm{T}_{\mathrm{H}} 2$ cell cytokines IL-4, IL-5, IL-13, and the chemokine eotaxin. This may occur via induction of Ox40 ligand in human bronchial epithelial cells by DEPs, leading to an increase in $\mathrm{T}_{\mathrm{H}} 2$ cell cytokines in the differentiated dendritic cells, which express Ox40. ${ }^{30}$ This is a fascinating area for future research in DEP toxicology and airway epithelial biology, one that remains relatively unexplored.

\section{Previous Findings on DEPs in Allergic Reactions Confirmed}

The current study confirms the previous findings of the biological effects of DEPs. In particular, Inoue and colleagues $^{31}$ also found KC and MIP (in this case, MIP- $1 \alpha$ ), to be important chemokines after DEP exposure. They exposed $\mathrm{NC} / \mathrm{Nga}$ mice, mice with high IgE production and a propensity to develop atopic-dermatitis-like skin lesions, ${ }^{32}$ to $100 \mu \mathrm{g}$ of DEPs intratracheally weekly for 6 weeks and assessed the effects on lung inflammation primarily. They found that $\mathrm{KC}$ and MIP- $1 \alpha$, both neutrophil chemokines, increased most significantly (approximately sevenfold) in the BAL fluid and the lung tissue. The lung lavage cells increased threefold after DEP exposure and these were mostly neutrophils and mononuclear cells. Not surprisingly, the majority of the increased cell influx into the lung was neutrophils. It is to be noted that although in the current study mice exposed only to DEPs without allergens did not develop a higher neutrophil response (or increased oxidative stress levels), in the study by Inoue et al ${ }^{31}$ DEP alone induced airway inflammation. Factors in NC/Nga mice that may contribute to the biological effects of DEPs are unknown, but may be related to the existing atopic microenvironment in these mice. In this regard, it is interesting to note DEPs alone 
induced airway inflammation in transgenic mice overexpressing IL-5. ${ }^{33}$

\section{DEP-Driven Neutrophil-Mediated Inflammation}

The basis for the selective potentiation of the neutrophil response among other leukocytes by DEPs in this study is not known, but intriguing. It has been reported that administration of DEPs in the nasal cavity in humans induced an increase in neutrophils, lymphocytes, and monocytes/macrophages, but not eosinophils, along with an induction of the chemokines RANTES (activation normal T cell expressed and secreted), MIP- $1 \alpha$, and MCP-3 (monocyte chemoattractant protein-3). ${ }^{34}$ Thus, DEPs appear to have the property of selectively inducing neutrophilic inflammation rather than eosinophilic inflammation. In this regard, neutrophilic inflammation is an important factor in some patients with severe asthma. ${ }^{35}$ The influx of neutrophils into the lung is certainly pronounced after viral and other infectious asthma exacerbations. More attention has been placed on identifying whether difficultto-control asthma patients have eosinophilic or neutrophilic inflammation by induced sputum cytology. In addition, patients with higher sputum neutrophil counts (>61\% total sputum cells) may have a better clinical response to a macrolide antibiotic, such as clarithromycin, including decreasing IL-8 levels. ${ }^{36}$ Further studies could focus on the potential anti-inflammatory role of macrolides in DEP-induced lung inflammation.

\section{Considerations for Future Studies}

The current study also supports a number of previous reports of the promotion of the inflammatory response and decline in lung function in humans by oxidative injury caused by exposure to air pollutants, in particular ozone. ${ }^{37-39}$ As investigators have proposed, enhancing the antioxidant defenses system of the airways could be a therapeutic strategy, especially for populations with increased DEPs exposure. Moreover, the role of endotoxin and other pathogens on diesel particulates needs to be considered further in future studies. Certainly, asthmatic patients have a "disordered lung microbiome" compared with age-matched control subjects. ${ }^{40}$ Bacteria may embed on DEPs and have a role in altering adaptive immune responses independent of endotoxin. This pathway is of increasing interest in the future of DEP research. Finally, it is now well known that not all PM are similar and this undoubtedly is true with DEPs. Recent epidemiologic and animal model studies have shown that NOx, elemental carbon, and other components of DEPs influence the development of asthma and atopy independently. Further narrowing the mechanisms, both common and independent, that lead to lung injury with these components will better enable us to think of new treatments and make better health care policies regarding diesel exhaust, transportation, and asthma.

\section{References}

1. Kim JNS, Vaickus LJ, Bouchard JC, Beal D, Cruikshang WW, Remick DG: Diesel exhaust particulates exacerbate asthma-like inflammation by increasing CXC chemokines. Am J Pathol 2011, 179:2730-2739

2. D'Amato G, Liccardi G, D'Amato M, Holgate S: Environmental risk factors and allergic bronchial asthma. Clin Exp Allergy 2005, 35: 1113-1124

3. Krzyzanowski M K-DB, Schneider J: Health effects of transport-related air pollution. Copenhagen: WHO Regional Office of Europe, 2005:190

4. Trasande L, Thurston GD: The role of air pollution in asthma and other pediatric morbidities. J Allergy Clin Immunol 2005, 115:689-699

5. Braback L, Forsberg B: Does traffic exhaust contribute to the development of asthma and allergic sensitization in children: findings from recent cohort studies. Environ Health 2009, 8:17

6. Dietert RR, Etzel RA, Chen D, Halonen M, Holladay SD, Jarabek AM, Landreth K, Peden DB, Pinkerton K, Smialowicz RJ, Zoetis T: Workshop to identify critical windows of exposure for children's health: immune and respiratory systems work group summary. Environ Health Perspect 2000, 108(Suppl 3):483-490

7. Nordling E, Berglind N, Melen E, Emenius G, Hallberg J, Nyberg F, Pershagen G, Svartengren M, Wickman M, Bellander T: Traffic-related air pollution and childhood respiratory symptoms, function and allergies. Epidemiology 2008, 19:401-408

8. Rosenlund M, Forastiere F, Porta D, De Sario M, Badaloni C, Perucci $\mathrm{CA}$ : Traffic-related air pollution in relation to respiratory symptoms, allergic sensitisation and lung function in schoolchildren. Thorax 2009, 64:573-580

9. Spira-Cohen A, Chen LC, Kendall M, Lall R, Thurston GD: Personal exposures to traffic-related air pollution and acute respiratory health among Bronx schoolchildren with asthma. Environ Health Perspect 2011, 119:559-565

10. Kim J, Merry AC, Nemzek JA, Bolgos GL, Siddiqui J, Remick DG: Eotaxin represents the principal eosinophil chemoattractant in a novel murine asthma model induced by house dust containing cockroach allergens. J Immunol 2001, 167:2808-2815

11. Kikuchi I, Kikuchi S, Kobayashi T, Hagiwara K, Sakamoto Y, Kanazawa M, Nagata M: Eosinophil trans-basement membrane migration induced by interleukin-8 and neutrophils. Am J Respir Cell Mol Biol 2006, 34:760-765

12. Donaldson K, Tran L, Jimenez LA, Duffin R, Newby DE, Mills N, MacNee W, Stone V: Combustion-derived nanoparticles: a review of their toxicology following inhalation exposure. Part Fibre Toxicol 2005, 2:10

13. Knaapen AM, Borm PJ, Albrecht C, Schins RP: Inhaled particles and lung cancer. Part A: mechanisms. Int J Cancer 2004, 109:799-809

14. Prahalad AK, Soukup JM, Inmon J, Willis R, Ghio AJ, Becker S, Gallagher JE: Ambient air particles: effects on cellular oxidant radical generation in relation to particulate elemental chemistry. Toxicol Appl Pharmacol 1999, 158:81-91

15. Tinkle SS, Antonini JM, Rich BA, Roberts JR, Salmen R, DePree K, Adkins EJ: Skin as a route of exposure and sensitization in chronic beryllium disease. Environ Health Perspect 2003, 111:1202-1208

16. Ohyama M, Otake T, Adachi S, Kobayashi T, Morinaga K: A comparison of the production of reactive oxygen species by suspended particulate matter and diesel exhaust particles with macrophages. Inhal Toxicol 2007, 19(Suppl 1):157-160

17. Nel AE, Diaz-Sanchez D, Li N: The role of particulate pollutants in pulmonary inflammation and asthma: evidence for the involvement of organic chemicals and oxidative stress. Curr Opin Pulm Med 2001, 7:20-26

18. DeForge LE, Fantone JC, Kenney JS, Remick DG: Oxygen radical scavengers selectively inhibit interleukin 8 production in human whole blood. J Clin Invest 1992, 90:2123-2129

19. Kim YJ, Kim D, Lee Y, Choi SY, Park J, Lee SY, Park JW, Kwon HJ: Effects of nanoparticulate saponin-platinum conjugates on 2,4-dinitrofluorobenzene-induced macrophage inflammatory protein-2 gene expression via reactive oxygen species production in RAW 264.7 cells. BMB Rep 2009, 42:304-309

20. Bowler RP: Oxidative stress in the pathogenesis of asthma. Curr Allergy Asthma Rep 2004, 4:116-122 
21. Maes T, Provoost S, Lanckacker EA, Cataldo DD, Vanoirbeek JA, Nemery B, Tournoy KG, Joos GF: Mouse models to unravel the role of inhaled pollutants on allergic sensitization and airway inflammation. Respir Res 2010, 11:7

22. Zhu Z, Oh SY, Zheng T, Kim YK: Immunomodulating effects of endotoxin in mouse models of allergic asthma. Clin Exp Allergy 2010, 40:536-546

23. Liu AH: Endotoxin exposure in allergy and asthma: reconciling a paradox. J Allergy Clin Immunol 2002, 109:379-392

24. Muranaka M, Suzuki S, Koizumi K, Takafuji S, Miyamoto T, Ikemori R, Tokiwa H: Adjuvant activity of diesel-exhaust particulates for the production of IgE antibody in mice. J Allergy Clin Immunol 1986, 77:616-623

25. Fujimaki H, Saneyoshi K, Shiraishi F, Imai T, Endo T: Inhalation of diesel exhaust enhances antigen-specific IgE antibody production in mice. Toxicology 1997, 116:227-233

26. Ichinose T, Takano $H$, Sadakane $K$, Yanagisawa $R$, Kawazato $H$, Sagai M, Shibamoto T: Differences in airway-inflammation development by house dust mite and diesel exhaust inhalation among mouse strains. Toxicol Appl Pharmacol 2003, 187:29-37

27. Yanagisawa R, Takano H, Inoue KI, Ichinose T, Sadakane K, Yoshino S, Yamaki K, Yoshikawa T, Hayakawa K: Components of diesel exhaust particles differentially affect Th1/Th2 response in a murine model of allergic airway inflammation. Clin Exp Allergy 2006, 36:386395

28. Matsumoto A, Hiramatsu K, Li Y, Azuma A, Kudoh S, Takizawa H, Sugawara I: Repeated exposure to low-dose diesel exhaust after allergen challenge exaggerates asthmatic responses in mice. Clin Immunol 2006, 121:227-235

29. Last JA, Ward R, Temple L, Pinkerton KE, Kenyon NJ: Ovalbumininduced airway inflammation and fibrosis in mice also exposed to ultrafine particles. Inhal Toxicol 2004, 16:93-102

30. Bleck B, Tse DB, Gordon T, Ahsan MR, Reibman J: Diesel exhaust particle-treated human bronchial epithelial cells upregulate Jagged-1 and OX40 ligand in myeloid dendritic cells via thymic stromal lymphopoietin. J Immunol 2010;185:6636-6645

31. Inoue K, Takano H, Yanagisawa R, Ichinose T, Shimada A, Yoshikawa T: Pulmonary exposure to diesel exhaust particles induces airway inflammation and cytokine expression in NC/Nga mice. Arch Toxico 2005, 79:595-599

32. Matsumoto M, Ra C, Kawamoto K, Sato H, Itakura A, Sawada J, Ushio $\mathrm{H}$, Suto $\mathrm{H}$, Mitsuishi K, Hikasa $\mathrm{Y}$, Matsuda $\mathrm{H}$ : IgE hyperproduction through enhanced tyrosine phosphorylation of Janus kinase 3 in NC/Nga mice, a model for human atopic dermatitis. J Immunol 1999 162:1056-1063

33. Hao M, Comier S, Wang M, Lee JJ, Nel A: Diesel exhaust particles exert acute effects on airway inflammation and function in murine allergen provocation models. J Allergy Clin Immunol 2003, 112:905914

34. Diaz-Sanchez D, Jyrala M, Ng D, Nel A, Saxon A: In vivo nasal challenge with diesel exhaust particles enhances expression of the CC chemokines rantes. MIP-1alpha, and MCP-3 in humans. Clin Immunol 2000, 97:140-145

35. Wenzel SE, Schwartz LB, Langmack EL, Halliday JL, Trudeau JB, Gibbs RL, Chu HW: Evidence that severe asthma can be divided pathologically into two inflammatory subtypes with distinct physiologic and clinical characteristics. Am J Respir Crit Care Med 1999 160:1001-1008

36. Simpson JL, Powell H, Boyle MJ, Scott RJ, Gibson PG: Clarithromycin Targets Neutrophilic Airway Inflammation in Refractory Asthma. AJRCCM 2008, 177:148-155

37. Vagaggini $B$, Carnevali S, Macchioni P, Taccola M, Fornai E, Bacci E, Bartoli ML, Cianchetti S, Dente FL, Di Franco A, Giannini D, Paggiaro $\mathrm{PL}$ : Airway inflammatory response to ozone in subjects with different asthma severity. Eur Respir J 1999, 13:274-280

38. Louis R, Lau LC, Bron AO, Roldaan AC, Radermecker M, Djukanovic $R$ : The relationship between airways inflammation and asthma severity. Am J Respir Crit Care Med 2000, 161:9-16

39. Kleeberger SR, Levitt RC, Zhang LY, Longphre M, Harkema J, Jedlicka A, Eleff SM, DiSilvestre D, Holroyd KJ: Linkage analysis of susceptibility to ozone-induced lung inflammation in inbred mice. Nat Genet 1997, 17:475-478

40. Hilty M, Burke C, Pedro H, Cardenas P, Bush A, Bossley C, Davies J, Ervine A, Poulter L, Pachter L, Moffatt MF, Cookson WO: Disordered microbial communities in asthmatic airways. PLoS One 5:e8578 